\title{
Factors with the strongest prognostic value associated with in-hospital mortality rate among patients operated for acute subdural and epidural hematoma
}

\author{
Bartłomiej Kulesza $^{1}$ (D) $\cdot$ Marek Mazurek $^{1} \cdot$ Adam Nogalski $^{2}$ (D) $\cdot$ Radosław Rola $^{1}$
}

Received: 13 June 2020 / Accepted: 5 August 2020 / Published online: 10 August 2020

(c) The Author(s) 2020

\begin{abstract}
Introduction Traumatic brain injury (TBI) still remains a serious health problem and is called a "silent epidemic". Each year in Europe 262 per 100,000 individuals suffer from TBI. The most common consequence of severe head injuries include acute subdural $(\mathrm{SDH})$ and epidural hematomas $(\mathrm{EDH})$, which usually require immediate surgically treatment. The aim of our study is to identify factors which have the strongest prognostic value in relation to in-hospital mortality rate among of patients undergoing surgery for EDH and SDH.

Patients and methods Cohort included 128 patients with isolated craniocerebral injuries who underwent surgery for EDH (28 patients) and SDH (100 patients) in a single, tertiary care Department of Neurosurgery. The data were collected on admission of patients to the Emergency Department and retrospectively analyzed. The following factors were analyzed: demographic data, physiological parameters, laboratory variables, computed tomography scan characteristics and the time between trauma and surgery. Likewise, we have investigated the in-hospital mortality of patients at the time of discharge.

Results We found that the factors with the strongest prognostic values were: the initial GCS score, respiratory rate, glycaemia, blood saturation, systolic blood pressure, midline shift and type of hematoma. Additionally, we proved that a drop by one point in the GCS score almost doubles the risk of in-hospital death while the presence of coagulopathy increases the risk of in-hospital death almost six times.

Conclusion Most of the factors with the strongest prognostic value are factors that the emergency team can treat prior to the hospital admission. Coagulopathy, however that has the strongest influence on in-hospital death rate can only be efficiently treated in a hospital setting.
\end{abstract}

Keywords Traumatic brain injury $\cdot$ Epidural hematoma $\cdot$ Subdural hematoma $\cdot$ In-hospital mortality rate

Bartłomiej Kulesza

kuleszabartek88@gmail.com

Marek Mazurek

marekmazurek@hotmail.com

Adam Nogalski

chirurgiaurazowalublin@tlen.pl

Radosław Rola

rola.radoslaw@gmail.com

1 Chair and Department of Neurosurgery and Paediatric Neurosurgery, Medical University in Lublin, Independent Public Clinical Hospital No. 4 in Lublin, Jaczewskiego 8, 20-954 Lublin, Poland

2 Chair and Department of Trauma Surgery and Emergency Medicine, Medical University in Lublin, Independent Public Clinical Hospital No. 1 in Lublin Poland, Stanisława Sztaszica 16, 20-400 Lublin, Poland

\section{Introduction}

Traumatic brain injury (TBI) still remains a serious health and socioeconomic problem being called a "silent epidemic" because the effects of trauma are often not immediately visible [1,2]. Moreover, TBI usually affects young adults and results in high mortality or severe disability. Each year in Europe 262 per 100,000 individuals suffer from TBI [3, 4]. The most common consequences of severe head injuries are extra-axial hemorrhagic lesions such as an acute subdural (SDH) and epidural hematoma (EDH), which usually require immediate surgically treatment [4-6]. 'No head injury is too severe to despair of, nor too trivial to ignore' - this the aphorism of Hippocrates shows that estimating the prognosis after head injury has been and remains difficult [7]. Most of the factors associated with mortality, however were analyzed 
on the basis of all types of TBI, not specifically in patients with EDH and SDH. The aim of our study is to identify factors which have the strongest prognostic value in relation to in-hospital mortality rate among of patients who undergo surgery for acute extra-axial hematoma, i.e. EDH and SDH.

\section{Patients and methods}

The study cohort included 128 patients with isolated craniocerebral injuries. The patients were divided into two groups, namely a group of 28 patients operated on due to epidural hematoma (EDH group) and a group of 100 operated on due to acute subdural hematoma (SDH group). All of the patients were operated and treated in the Department of Neurosurgery and Pediatric Neurosurgery of the Independent Public Clinical Hospital No. 4 (IPCH 4) in Lublin, from 1.10.2014 to 31.08.2017. All patients underwent craniotomy and hematoma evacuation. During this period, 162 patients underwent surgery for extra-axial hematoma whereas 34 patients were excluded from the study due to: the lack of complete medical documentation, incomplete laboratory tests or the lack of formal description of the computed tomography of the head and patients undergoing decompression craniectomy (Fig. 1).

All of the data were collected retrospectively based on the admission data from the Emergency Department (ED). All of the physiological factors were collected up to $10 \mathrm{~min}$ after the patient's arrival in ED. Blood was taken for laboratory tests and computed tomography of the head was performed up to 30 min after arrival in ED. The following variables were analyzed: demographic data (gender and age), physiological factors, laboratory variables, computed tomography scan characteristics and the time between trauma and surgery. Physiological factors included initial GCS score, pupil reaction to light, saturation, systolic blood pressure (SBP), heart rate (HR) and respiratory rate (RR). Laboratory variables included: the number of white blood cells (WBC), hemoglobin (HGB) value, number of platelets (PLT), glycemia value, sodium concentration, and coagulopathy and alcohol levels. Each patient included in the study had a computed tomography (CT) of the head on admission. The study aimed at particular characteristics from the $\mathrm{CT}$, such as the present skull fracture, subarachnoid hemorrhage (SAH),

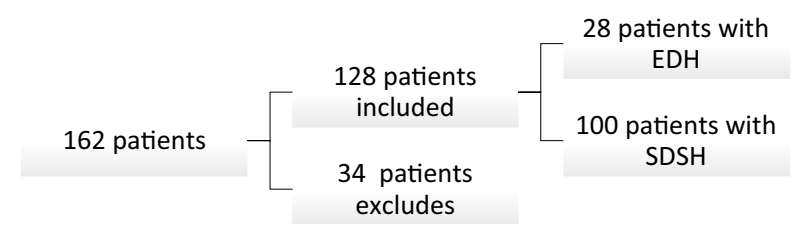

Fig. 1 Patients inclusion scheme intraventricular hemorrhage (IVH), cerebral contusion, maximum thickness of the hematoma, midline shift (MLS) and state of basal cisterns. The midline shift and maximum thickness of the hematoma were calculated using the OsiriX version 2.5 program based on cross sections from the preoperative CT scan. The last factor was the time between the injury and the surgery. The in-hospitality mortality of patients was assessed at the time of discharge. Statistical analysis correlated all of the aforementioned factors with in-hospital mortality rate.

\section{Statistical analysis}

In univariate analysis, the $\mathrm{Chi}^{2}$ homogeneity test was performed to detect differences in unrelated qualitative characteristics between groups. In multivariate analysis, the logistic regression analysis was used to assess the factors with predominant prognostic value of the in-hospital mortality. If applicable, for comparison of two independent variables the Mann-Whitney $U$ test was implemented. A significance level of $p<0.05$ was assumed indicating the existence of statistically significant differences. In the logistic regression analysis, all the studied factors were considered. For the obtained model, the $\mathrm{Chi}^{2}$ value for the difference between the current model and the model with only the free expression was highly statistically significant $(p<0.00001)$. The database and statistical research were based on the STATISTICA 13.0 computer software (StatSoft, Poland).

\section{Results}

The mean age of patients with EDH was $38.81 \pm 13.37$ years and it was significantly lower than the mean age of patients in SDH group-57.86 \pm 18.26 years $(p=0.00001)$. Men were hospitalized most often than women. The patients with SDH had lower GCS scores than those in EDH group $(p=0.004)$. Death during hospitalization was more frequent in patients with subdural hematoma (45\%) when compared to the group with epidural hematoma $(10.71 \%),(p=0.0009)$ (Table 1). The time to death (in-hospital mortality) was slightly longer in the EDH group (median 4 days) in comparison to the SDH group (median 3 days). The difference was not statistically significant ( $p=0.71$ ), though (Fig. 1 ).

\section{Evaluation of the factors showing the strongest prognostic value regarding in-hospital mortality rate}

The factors that entered the model and had a significant relationship with the mortality rate at the level of $p<0.05$ were: the initial GCS scale, type of hematoma, maximum thickness of hematoma, status of basal cisterns and coagulopathy. 
Table 1 Comparison of factors with $p<0.05$ in both groups

\begin{tabular}{|c|c|c|c|c|c|}
\hline \multirow[t]{2}{*}{ Factors } & \multicolumn{2}{|c|}{$\mathrm{EDH}(n=28)$} & \multicolumn{2}{|c|}{$\mathrm{SDH}(n=100$} & \multirow[t]{2}{*}{ Statistical analysis } \\
\hline & $\bar{N}$ & $\%$ & $n$ & $\%$ & \\
\hline \multicolumn{6}{|l|}{ Gender } \\
\hline Female & 2 & 7.14 & 14 & 14.00 & \multirow[t]{2}{*}{$p=0.00001$} \\
\hline Male & 26 & 92.86 & 86 & 86.00 & \\
\hline \multicolumn{6}{|l|}{ Age } \\
\hline$<35$ years old & 10 & 35.71 & 14 & 14.00 & \\
\hline 36-60 years old & 17 & 60.71 & 42 & 42.00 & \\
\hline$>61$ years old & 1 & 3.57 & 44 & 44.00 & \\
\hline \multicolumn{6}{|l|}{ GCS score } \\
\hline 3-8 score GCS & 9 & 32.14 & 60 & 60.00 & \multirow[t]{3}{*}{$p=0.004$} \\
\hline 9-12 score GCS & 7 & 25.00 & 25 & 25.00 & \\
\hline 13-15 score GCS & 12 & 42.86 & 15 & 15.00 & \\
\hline In-hospital mortality & 3 & 10.71 & 45 & 45.00 & $p=0.0009$ \\
\hline
\end{tabular}

$p$ statistical value
The rest of the tested factors with a level of $p \geq 0.05$ did not enter the model. The obtained logistic model is presented below: factors of in-hospital mortality, it was shown that the variables included in the table and the figures below are important variables for the assessment of death and survival during

$P(X) \frac{e^{4.834+0,551 \text { initial GCS scale-3.279type of hematoma-maximum thickness of hematoma-1.696status of basal cisterns }+1.770 \text { coagulopathy }}}{1+e^{4.834+0.551 \text { initial GCS scale-3.279type of hematoma-maximum thickness of hematoma-1.696status of basal cisterns }+1.770 \text { coagulopathy }}}$

The model shows that a drop by four points in the GCS score affects the increased risk of in-hospital death almost twice (1.73). The presence of epidural hematoma increases the survival charter by 0.04 compared to patients with subdural hematoma. Similarly, the smaller the maximum thickness of hematomas by $10 \mathrm{~mm}$, the death risk is almost one time lower (0.88). Normal size basal cisterns increase the survival chance by 0.18 , while the presence of coagulopathy (INR $>1.2$ or PT $>12.7 \mathrm{~s}$ ) increases the risk of in-hospital death (almost six times) (5.87). The results obtained are presented in the table below (Table 2).

As a result of the analysis using Data Mining, the selection and the elimination of variables to assess the prognostic hospitalization. The factors with the strongest prognostic value are: the initial GCS score, respiratory rate (below 10 or above 25 breaths per min), hyperglycemia (blood glucose level $>110 \mathrm{mg} / \mathrm{dl}$ ), saturation (oxygen saturation $<96 \%$ ), systolic blood pressure (below 90 or above $140 \mathrm{mmHg}$ ), midline shift and type of hematoma (Table 3) and (Fig. 2).

\section{Discussion}

\section{Demographic data}

Observations to date have often indicated the impact of demographic factors such as age and gender on the prognosis
Table 2 Logistic model for the assessment of prognostic factors of in-hospital mortality in both groups

\begin{tabular}{lcrrrrr}
\hline & Constant & GCS scale & Type of hematoma & $\begin{array}{l}\text { Maximum } \\
\text { thickness of } \\
\text { hematoma }\end{array}$ & $\begin{array}{l}\text { Status } \\
\text { of basal } \\
\text { cisterns }\end{array}$ & Coagulopathy \\
\hline Rating & 4.8363 & 0.5506 & -3.2790 & -0.1305 & -1.6964 & 1.7697 \\
Standard error & 2.3359 & 0.1161 & 1.4588 & 0.0531 & 0.6379 & 0.8487 \\
$t(122)$ & 2.0704 & 4.7408 & -2.2478 & -2.4580 & -2.6592 & 2.0852 \\
$p$ & 0.0405 & 0.0000 & 0.0264 & 0.0154 & 0.0089 & 0.0392 \\
$-95 \%$ CL & 0.2118 & 0.3207 & -6.1670 & -0.2355 & -2.9593 & 0.0895 \\
$+95 \%$ CL & 9.4608 & 0.7806 & -0.3910 & -0.0254 & -0.4334 & 3.4500 \\
Chi $^{2}$ Walda & 4.2867 & 22.4751 & 5.0526 & 6.0420 & 7.0716 & 4.3480 \\
\hline
\end{tabular}

Statistical analysis: $\mathrm{Chi}^{2}=91.53 ; p<0.00001$ 
Table 3 Dominant factors for the dependent variables of the in-hospital mortality

\begin{tabular}{lll}
\hline Factors & $\mathrm{Chi}^{2}$ & $P$ \\
\hline Initial GCS scale & 45.05 & 0.000000 \\
RR & 27.88 & 0.000000 \\
Glycaemia & 22.50 & 0.000002 \\
Saturation & 20.19 & 0.000007 \\
SBP & 13.03 & 0.0003 \\
MLS & 25.45 & 0.0006 \\
Type of hematoma & 10.97 & 0.0009 \\
Pupil reactive & 10.80 & 0.001 \\
IVH & 7.65 & 0.01 \\
SAH & 7.07 & 0.01 \\
Status of basal cisterns & 4.65 & 0.03 \\
\hline
\end{tabular}

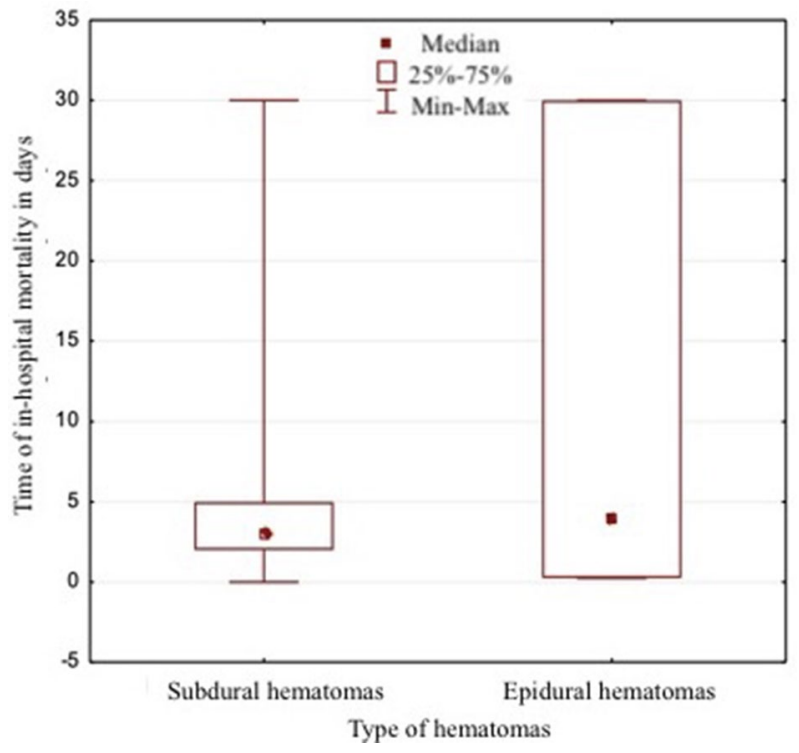

Fig. 2 Time in-hospital mortality

of patients with TBI. Analysis carried out by Pozzato et al. on 6827 people hospitalized due to TBI showed that the risk of severe trauma is highest at age 15-19 and over 75 . The authors estimated that for the latter group it is three times larger than for the general population [8]. A metaanalysis by Hukkelhoven et al. [9] showed that only $15 \%$ of patients over 65 years of age have a positive prognosis after severe head injury. Similar conclusions were made by Perel et al. [10] stating that increasing age above 40 -years old was associated with higher mortality rate, creating approximately linear function. The relationship between age, unfavorable prognosis and the mortality rate were also seen in the works of other authors [11-17]. It is probably associated with lower regenerative abilities and greater sensitivity of the brain tissue of older people to ischemia as well as frequent coexistence of other diseases in this age group [18-20]. However, our observations did not indicate age among the factors with the strongest predictive value in relation to the in-hospital mortality rate. Some authors pointed to the existence of a difference in the prognosis of traumatic patients depending on the patient's sex [21]. However, there is strong evidence that gender did not affect the prognosis in TBI [11, 22-26]. This is also confirmed by the results of our observations (Fig. 3).

\section{Physiological factors}

The Glasgow Coma Scale (GCS) is one of the basic tools used to assess the condition of patients after head injuries. It is used not only to assess the victim's state of consciousness, but it can also be useful in predicting the condition of patients in the following days after injury [27]. Likewise, our data prove a strong impact of GCS and the pupil response on the outcome and mortality rate of patients operated on for extra-axial hematoma [28-30]. This relationship was also strongly marked in the observations of other authors $[11,15$, 31-34]. Importantly, the multivariate analysis placed GCS score and pupil response to light among the factors with the strongest prognostic value and our studies showed that a drop by one point in the GCS score almost doubles the risk of in-hospital death. However, it should be noted that some authors did not notice similar trends [26].

The Glasgow scale is a very useful tool, but the strategy of dealing with trauma patients cannot depend only on this indicator. It has been proved that the score is related to a number of parameters such as drug and alcohol intoxication, medical sedation, hypotension or hypoxia, often independent of the injury [12]. Hypotension and hypoxia following TBI are recognized as a significant secondary disorder associated with a poor outcome [35]. Petroni et al. found a very

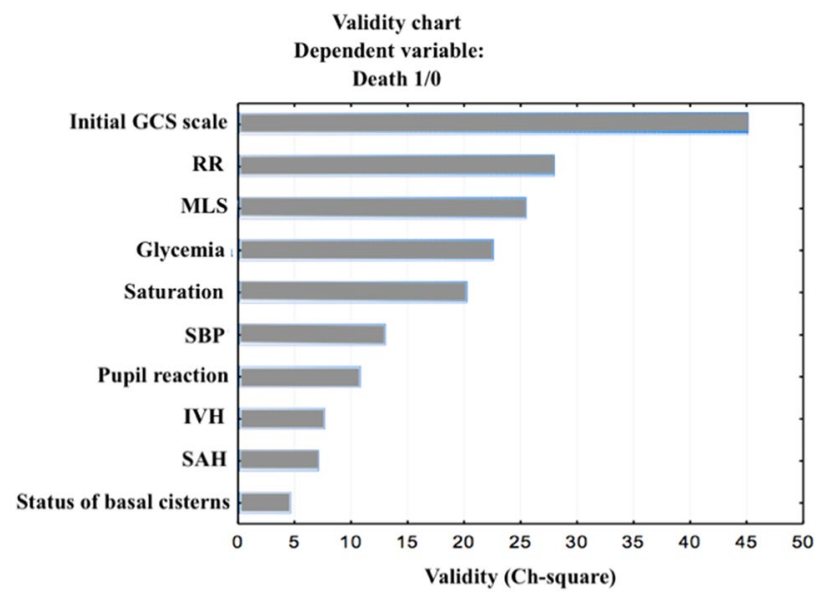

Fig. 3 Dominant factors for the dependent variables of the in-hospital mortality 
strong relationship between low blood pressure and mortality. Hypotension ( SBP $<90 \mathrm{mmHg}$ ) was associated with $90 \%$ mortality rate [36]. The values of SBP higher than 135 or even 150 or lower than $90 \mathrm{mmHg}$ were associated with poorer outcomes [22, 37]. Similarly, our Data Mining analysis placed SBP and saturation amongst the dominant factors that influence mortality with a high statistical significance $(p<0.0003)$.

The impact of other vital signs on the prognosis of patients with TBI was also analyzed. Respiratory rate higher than 25 and lower than 10 increased mortality rates. Similarly, heart rates beyond a normal range are associated with a poor outcome in TBI [37]. The role of respiratory failure was also emphasized in the work of other authors. Osterman et al. [11] showed that mortality among patients after TBI with coexisting respiratory failure reaches $79.3 \%$. It should be emphasized that our research placed RR among the factors closely correlating with mortality $(p<0.0000001)$. Oxygen saturation is yet another indicator directly related to mortality rates following TBI. Kalayci et al. [38] studied the patients undergoing craniectomy for SDH and proved that the saturation less than or equal to $96 \%$ was significantly associated with higher mortality rates $(p=0.004)$.

\section{Laboratory variables}

Laboratory variable in TBI patients have also been frequently analyzed in the literature. One of them is stress hyperglycemia, a common finding after the injury [39]. High glucose is a cause of secondary insults for the patients after TBI, and it is associated with a poorer outcome [40]. This trend was also noted in observations carried out by Bobeff et al. The authors showed that patients with glucose levels exceeding $160 \mathrm{mg} / \mathrm{dL}$ are at a higher risk of complications after treatment [41]. Similarly, the work of Corbett et al. [42] showed that disorders in this area are associated with higher risk of unfavorable outcome at 18 months after severe TBI. Likewise, in our study hyperglycemia placed among the factors with the strongest prognostic value concerning in-hospital mortality $(p=0.000002)$.

Many authors also considered the relationship between electrolyte balance and the condition of patients after injury. It has been shown that both hypo- and hypernatremia are associated with a poorer outcome, thus sodium revealed a $U$ shaped relationship with the outcome [5, 40, 43]. Importantly, hypo-natremia is a relatively infrequent occurrence on admission following TBI. Contrariwise, our study did not confirm the effects of hypo- and hypernatremia on inhospital mortality.

TBI-associated changes may also be seen in patients' blood counts. Bobeff et al. [41] showed that abnormalities in hematological parameters such as hemoglobin $(\mathrm{Hg})$, hematocrit (Ht), and red blood cell count (RBC) are an independent risk factor for unfavorable prognosis. Interestingly, the authors also emphasized the role of red blood cell distribution width (RDW) and platelet count disorders in predicting patient mortality. A similar analysis was carried out by Corbett et al. In this study, the association of abnormalities of hemoglobin on admission with a higher risk of adverse prognosis was present during the first 18 months after major TBI. No such relationship was found for the parameters of the white blood cell system (neutrophil and lymphocyte counts), which was previously presented by other authors [42, 44]. Our analysis did not reveal any relationship between abnormalities in blood morphotic systems and in-hospital mortality.

Interestingly, Corbett et al. [42] also showed a relationship between fibrinogen metabolism changes, activated partial thromboplastin time (APTT), international normalized ratio (INR) and disseminated intravascular coagulation score (DIC score) and a greater risk of unsuccessful prognosis within 18 months after the injury. The authors attributed a special predictive value to INR [42]. Likewise, Fuji et al. [45] studying patients who underwent surgery for intracranial hematomas, found that lower values of INR and PTT ensured remarkably better outcomes than higher ones. Coagulopathies, especially changes in prothrombin time and platelet counts, are major determinants of disability and death among the patients with traumatic intracranial hemorrhage [39, 40]. Epstein et al. [46] in their meta-analysis covering 22 studies determined the average percentage of patients with TBI who develop coagulopathy at $35.2 \%$. A convergent correlation was seen in the work of Yuan et al. They estimated that this problem affects $18.6 \%$ of patients after isolated TBI, but increases to $30.4 \%$ in serious injuries. The authors also showed that patients with severe TBI were characterized by higher INR, prothrombin time (PT), APTT, D-dimer level and lower PLT and fibrinogen levels [31]. Earlier studies defined PT as the indicator most often disturbed in the case of TBI, but APTT seems to correlate better with prognosis and mortality among patients [47-50]. Importantly, our multivariate analysis showed that the presence of any coagulopathy increases the risk of in-hospital death almost six times.

Alcohol consumption was also found to be an important risk factor for TBI, with the prevalence of alcohol intoxication between 20 and 55\% at the time of the injury [51, 52]. In our study $31.25 \%$ patients were under the influence of alcohol. Alcohol intoxication was associated with a poorer outcome after a severe TBI [15, 52]. On the other hand, it is associated with a decreased mortality [53], thus the relationship between alcohol and the outcome after TBI remains uncertain [53-55]. Our results did not include alcohol in the factors affecting mortality. 


\section{Computer tomography scan characteristics}

Imaging studies currently play a key role in the management of head injuries. Strong evidence was found for the midline shift $[27,56,57]$ and a greater increase of the midline shift associated with a higher mortality $[56,58]$. Ostermann et al. [11] in their observations of 265 elderly patients after TBI showed that midline shifts affect $25 \%$ of them. At the same time, they stated that shift over $15 \mathrm{~mm}$ is associated with a significantly higher risk of death. In a large analysis of 861 patients after TBI Nelson et al. [59] identified midline shift as the most important risk factor for adverse prognosis. The authors studying patients with $\mathrm{EDH}$ and SDH found a higher mortality associated with a greater midline shift, as well as the thickness of hematoma [26, $29,30]$. Our multivariate analysis confirms these relationships between MLS and mortality rate $(p=0.0006)$.

The presence of a traumatic subarachnoid hemorrhage and intraventricular hemorrhage predicts higher mortality $[5,27,56,60]$. Our multivariate analysis using Data Mining demonstrates that SAH and IVH are both significantly associated with the mortality rate $(p=0.01)$. The next factor associated with in-hospital mortality were the type of hematoma and status of basal cisterns in multivariate analysis $(p=0.0009$ and $p=0.03)$. In-hospital mortality in EDH group was $10.71 \%$ while in SDH group-45\%. Grigorakos et al. found the highest mortality rate in SDH $(43.75 \%)$ in comparison with other post-traumatic changes seen in computed tomography [61]. Khaled et al. found mortality rate among patients with EDH at $10.66 \%$ [24]. Status of basal cisterns was closely associated with mortality $[10,22,58$, 62]. Our research showed that all these factors significantly correlated with mortality; in addition the presence of EDH increases the survival chances when compared to patients with SDH. Similarly, the smaller the maximum thickness of hematomas, the death risk is lower. Normal size basal cisterns increase the survival chance by 0.18 .

The presence of skull fractures may also be important. On the one hand, thanks to mechanical damage, some of the energy is absorbed, which would otherwise be transferred directly to the sensitive brain tissue. On the other hand, the presence of fractures directly testifies to the large force causing the injury [63]. The skull fracture among TBI patients is associated with an increased risk of neurosurgically-relevant intracranial lesion [64]. Bobeff et al. showed a higher incidence of complications during treatment in patients with linear skull fracture [41]. Our results did not include fractures as factors of unfavorable prognosis.

\section{Time between injury and operation}

Most researchers agree that delaying the moment of surgical treatment implementation negatively affects the survival and prognosis of patients [29, 65, 68, 69]. Matsushima et al. [70] showed that in-hospital mortality was significantly lower in the group of patients operated on within up to $200 \mathrm{~min}$ after the arrival at the emergency department $(p=0.03)$. Seelig et al. [71] studying the patients undergoing surgery for SDH, found that the surgery would reduce mortality from 90 to $30 \%$ within $4 \mathrm{~h}$. On the other hand, there are still a few studies that did not associate a shorter period of time between the injury and the surgery with the outcome $[26,72,73]$. Our statistical analysis shown no association between time to surgery and in-hospital mortality, but it was reasonable to perform a surgery as soon as possible.

\section{Conclusion}

Amongst the contempororary literature on the patients with a traumatic brain injury, only a few of the studies analyzed a selected group of patients operated on due to the extra-axial hematomas. We were unable to find a study which would collectively analyze all of the factors which we examined in our cohort of patients operated on due to epi and subdural hematomas. Accordingly, we identified a group of the most important factors that highly significantly $(p \leq 0.000007)$ correlate with the in-hospital mortality rate such as: the initial GCS scale, respiratory rate, glycaemia, and saturation. Apart from the GCS scale, these are the factors that can be effectively treated outside the hospital by the ambulance team, which may eventually result in decreased mortality rate. The presence of coagulopathy, however, which increases the risk of in-hospital mortality rate almost six times can be effectively treated only in a hospital setting. Therefore, a prompt transportation to the hospital is also of the paramount importance since the treatment for coagulopathy should be introduced as soon as possible.

Our results require confirmation in other studies on a larger group of patients because this study have significant limitations. First, it included relatively small number of patients operated on for epidural hematoma. Second, no patients conservatively treated due to TBI were included in the study, while a large group of patients after TBI such as those with brain contusions and small intracranial hematomas with no mass effect do not require surgery in the first line treatment. We also did not consider other factors such as blood gas, hematoma volume, C-reactive protein levels, D-dimer and thyroid-stimulating hormone in the study.

Funding This research did not receive any specific grant from funding agencies in the public, commercial, or not-for-profit sectors.

\section{Compliance with ethical standards}

Conflict of interest Bartłomiej Kulesza, Marek Mazurek, Adam Nogalski and Radosław Rola declare that they have no conflict of interest. 
Consent ethics commission The study obtained the consent of the Bioethics Commission located at Medical University of Lublin. Number of consent KE-0254/313/2016.

Open Access This article is licensed under a Creative Commons Attribution 4.0 International License, which permits use, sharing, adaptation, distribution and reproduction in any medium or format, as long as you give appropriate credit to the original author(s) and the source, provide a link to the Creative Commons licence, and indicate if changes were made. The images or other third party material in this article are included in the article's Creative Commons licence, unless indicated otherwise in a credit line to the material. If material is not included in the article's Creative Commons licence and your intended use is not permitted by statutory regulation or exceeds the permitted use, you will need to obtain permission directly from the copyright holder. To view a copy of this licence, visit http://creativecommons.org/licenses/by/4.0/.

\section{References:}

1. Ghajar J. Traumatic brain injury. Lancet. 2000;356:923-9.

2. Koskinen S, Alaranta H. Traumatic brain injury in Finland 1991-2005: a nationwide register study of hospitalized and fatal TBI. Brain Inj. 2008;22:205-14.

3. Peeters W, van den Brande R, Polinder S, Brazinova A, Steyerberg EW, Lingsma HF, Maas AI. Epidemiology of traumatic brain injury in Europe. Acta Neurochir. 2015;157:1683-96.

4. Dewan MC, Rattani A, Gupta S, Baticulon RE, Hung YC, Punchak M, Agrawal A, Adeleye AO, Shrime MG, Rubiano AM, Rosenfeld JV, Park KB. Estimating the global incidence of traumatic brain injury. J Neurosurg. 2018. https://doi. org/10.3171/2017.10.JNS17352.

5. Kulesza B, Litak J, Grochowski C, Nogalski A, Rola R. The initial factors with strong predictive value in relation to six-month outcome among patients operated due to extra-axial hematomas. Diagnostics. 2020;10(3):174. https://doi.org/10.3390/diagnostic s10030174.

6. Kulesza B, Mazurek M, Rams L, Nogalski A. Acute epidural and subdural hematomas after head injury: clinical distinguishing features. Indian J Surg. 2020. https://doi.org/10.1007/s1226 2-020-02304-w.

7. Hukkelhoven CW, Steyerberg EW, Habbema JD, Farace E, Marmarou A, Murray GD, Marshall LF, Maas AI. Predicting outcome after traumatic brain injury: development and international validation of prognostic scores based on admission characteristics. J Neurotrauma. 2005;22(10):1025-39.

8. Pozzato I, Tate RL, Rosenkoetter U, Cameron ID. Epidemiology of hospitalised traumatic brain injury in the state of New South Wales, Australia: a population-based study. Aust N Z J Public Health. 2019;43(4):382-8. https://doi.org/10.1111/17536405.12878 (Epub 2019 Mar 4).

9. Hukkelhoven CW, Steyerberg EW, Rampen AJ, Farace E, Habbema JD, Marshall LF, Murray GD, Maas AI. Patient age and outcome following severe traumatic brain injury: an analysis of 5600 patients. J Neurosurg. 2003;99:666-73.

10. MRC CRASH Trial Collaborators, Perel P, Arango M, Clayton T, Edwards P, Komolafe E, Poccock S, Roberts I, Shakur H, Steyerberg E, Yutthakasemsunt S. Predicting outcome after traumatic brain injury: practical prognostic models based on large cohort of international patients. BMJ. 2008;336(7641):425-9.

11. Ostermann RC, Joestl J, Tiefenboeck TM, Lang N, Platzer P, Hofbauer M. Risk factors predicting prognosis and outcome of elderly patients with isolated traumatic brain injury. J Orthop
Surg Res. 2018;13(1):277. https://doi.org/10.1186/s13018-0180975-y (Published 2018 Nov 3).

12. Fu TS, Jing R, McFaull SR, Cusimano MD. Recent trends in hospitalization and in-hospital mortality associated with traumatic brain injury in Canada: a nationwide, population-based study. J Trauma Acute Care Surg. 2015;79:449-54.

13 Susman M, DiRusso SM, Sullivan T, Risucci D, Nealon P, Cuff S, Haider A, Benzil D. Traumatic brain injury in the elderly: increased mortality and worse functional outcome at discharge despite lower injury severity. J Trauma. 2002;53:219-23 (discussion 223-214).

14. Mosenthal AC, Livingston DH, Lavery RF, Knudson MM, Lee S, Morabito D, Manley GT, Nathens A, Jurkovich G, Hoyt DB, Coimbra R. The effect of age on functional outcome in mild traumatic brain injury: 6-month report of a prospective multicenter trial. J Trauma. 2004;56:1042-8.

15. Einarsen CE, van der Naalt J, Jacobs B, Follestad T, Moen KG, Vik A, Håberg AK, Skandsen T. Moderate traumatic brain injury: clinical characteristics and a prognostic model of 12-month outcome. World Neurosurg. 2018;114:e1199e1210210. https://doi.org/10.1016/j.wneu.2018.03.176 (Epub 2018 Mar 31).

16. Roe C, Skandsen T, Manskow U, Ader T, Anke A. Mortality and one-year functional outcome in elderly and very old patients with severe traumatic brain injuries: observed and predicted. Behav Neurol. 2015;2015:845-9.

17. de Guise E, LeBlanc J, Dagher J, Tinawi S, Lamoureux J, Marcoux J, Maleki M, Feyz M. Traumatic brain injury in the elderly: a level 1 trauma centre study. Brain Inj. 2015;29:558-64.

18. Ushewokunze S, Nannapaneni R, Gregson BA, Stobbart L, Chambers IR, Mendelow AD. Elderly patients with severe head injury in coma from the outset-has anything changed? $\mathrm{Br} \mathrm{J}$ Neurosurg. 2004;18:604-7.

19. Mina AA, Knipfer JF, Park DY, Bair HA, Howells GA, Bendick PJ. Intracranial complications of preinjury anticoagulation in trauma patients with head injury. J Trauma. 2002;53:668-72.

20. Mohindra S, Mukherjee KK, Gupta R, Chhabra R. Continuation of poor surgical outcome after elderly brain injury. Surg Neurol. 2008;69:474-7.

21 Kada AY, Bouyoucef KA. La mort encéphalique post traumatique: épidémiologie et facteurs de risque [Post traumatic brain death: epidemiology and risk factors]. Pan Afr Med J. 2018;31:29. https ://doi.org/10.11604/pamj.2018.31.29.16354 (Published 2018 Sep 13).

22. Murray GD, Butcher I, McHugh GS, Lu J, Mushkudiani NA, Maas AI, Marmarou A, Steyerberg EW. Multivariable prognostic analysis in traumatic brain injury: results from the IMPACT study. J Neurotrauma. 2007;24(2):329-37.

23. Mushkudiani NA, Engel DC, Steyerberg EW, Butcher I, Lu J, Marmarou A, Slieker F, McHugh GS, Murray GD, Maas AI. Prognostic value of demographic characteristics in traumatic brain injury: results from the IMPACT study. J Neurotrauma. 2007;24(2):259-69.

24. Khaled CN, Raihan MZ, Chowdhury FH. Surgical management of traumatic extradural hematoma: experiences with 610 patients and prospective analysis. Ind J Neurotrauma. 2008;2:75-9.

25. Khan KA, Choudhary M, Sinha VD, Gora N, Bairwa M. Predictors of outcome after traumatic brain injuries: experience of a tertiary health care institution in Northwest India. World Neurosurg. 2019;126:e699-e705. https://doi.org/10.1016/j.wneu.2019.02.126 (Epub 2019 Mar 4).

26. Baucher G, Troude L, Pauly V, Bernard F, Zieleskiewicz L, Roche $\mathrm{PH}$. Predictive factors of poor prognosis after surgical management of traumatic acute subdural hematomas: a single-center series. World Neurosurg. 2019;126:e944-e952952. https://doi. org/10.1016/j.wneu.2019.02.194 (Epub 2019 Mar 12). 
27. Kulesza B, Litak J, Mazurek M, Nogalski A. The initial factors affecting 6-month outcome of patients undergoing surgery for acute post-traumatic subdural and epidural hematoma. Folia Med (Plovdiv). 2020;62(1):94-104. https://doi.org/10.3897/folmed.62. e47743.

28. Taussky P, Widmer HR, Takala J, Fandino J. Outcome after acute traumatic subdural and epidural haematoma in Switzerland: a single-centre experience. Swiss Med Wkly. 2008;138:281-5.

29. Gurer B, Kertmen H, Yilmaz ER, Dolgun H, Hasturk AE, Sekerci $\mathrm{Z}$. The surgical outcome of traumatic extraaxial hematomas causing brain herniation. Turk Neurosurg. 2017;27(1):37-52.

30. Hamed M, Schuss P, Daher FH, Borger V, Güresir A, Vatter H, Güresir E. Acute traumatic subdural hematoma: surgical management in the presence of cerebral herniation-a singlecenter series and multivariate analysis. World Neurosurg. 2016;94:501-6.

31. Yuan Q, Yu J, Wu X, Sun Y, Li Z, Du Z, Wu X, Hu J, corresponding author. Prognostic value of coagulation tests for in-hospital mortality in patients with traumatic brain injury. Scand J Trauma Resusc Emerg Med. 2018;26(1):3. https://doi.org/10.1186/s1304 9-017-0471-0 (Published 2018 Jan 5).

32. Steyerberg EW, Mushkudiani N, Perel P, Butcher I, Lu J, McHugh GS, Murray GD, Marmarou A, Roberts I, Habbema DF, Maas AI. Predicting outcome after traumatic brain injury: development and international validation of prognostic scores based on admission characteristics. PLoS Med. 2008;5:e165.

33. Jacobs B, Beems T, van der Vliet TM, van Vugt AB, Hoedemaekers C, Horn J, Franschman G, Haitsma I, Naalt J, Andriessen TM, Borm GF, Vos PE. Outcome prediction in moderate and severe traumatic brain injury: a focus on computed tomography variables. Neurocrit Care. 2013;19:79-89.

34. Roozenbeek B, Lingsma HF, Lecky FE, Lu J, Weir J, Butcher I, et al. Prediction of outcome after moderate and severe traumatic brain injury: external validation of the International Mission on Prognosis and Analysis of Clinical Trials (IMPACT) and Corticoid Randomisation After Significant Head injury (CRASH) prognostic models. Crit Care Med. 2012;40:1609-17.

35. McHugh GS, Engel DC, Butcher I, Steyerberg EW, Lu J, Mushkudiani N, Hernández AV, Marmarou A, Maas AI, Gordon DM. Prognostic value of secondary insults in traumatic brain injury: results from the IMPACT study. J Neurotrauma. 2007;24(2):287-93.

36. Petroni G, Quaglino M, Lu jan S, Kovalevski L, Rondina C, Videtta W, Carney N, Nancy T, Randall C. Early prognosis of severe traumatic brain injury in an urban argentinian trauma center. J Trauma. 2010;68:564-70.

37. Saadat S, Akbari H, Khorramirouz R, et al. Determinants of mortality in patients with traumatic brain injury. Ulus Travma Acil Cerrahi Derg. 2012;18(3):219-24

38. Kalayci M, Aktunç E, Gül S, Hanci V, Edebali N, Cagavi F, Açikgöz B. Decompressive craniectomy for acute subdural haematoma: an overview of current prognostic factors and a discussion about some novel prognostic parametres. J Pak Med Assoc. 2013;63:34-49.

39. Joseph B, Aziz H, Zangbar B, Kulvatunyou N, Pandit V, O'Keeffe T, Tang A, Wynne J, Friese RS, Rhee P. Acquired coagulopathy of traumatic brain injury defined by routine laboratory tests: Which laboratory values matter? J Trauma Acute Care Surg. 2014;76(1):121-5.

40. Van Beek JG, Mushkudiani NA, Steyerberg EW, Butcher I, McHugh GS, Lu J, Marmarou A, Murray GD, Maas AI. Prognostic value of admission laboratory parameters in traumatic brain injury: results from the IMPACT study. J Neurotrauma. 2007;24(2):315-28.

41. Bobeff EJ, Posmyk BJ, Bobeff KŁ, Fortuniak J, Wiśniewski K, Stawiski K, Stefańczyk L, Jaskólski DJ. Predicting outcome and conservative treatment failure in patients with skull fracture after traumatic brain injury: a retrospective cohort study. J Neurol Surg A Cent Eur Neurosurg. 2019;80(6):460-9. https://doi. org/10.1055/s-0039-1692672 (Epub 2019 Aug 29).

42. Corbett JM, Ho KM, Honeybul S. Prognostic significance of abnormal hematological parameters in severe traumatic brain injury requiring decompressive craniectomy. J Neurosurg. 2019;132(2):545-51. https://doi.org/10.3171/2018.10.JNS18 2293.

43. Rejeb I, Chakroun O, Chtara K, Boujelbene M, Ksibi H, Chaari A, Bahloul M, Rekik N. Factors predicting early outcome in patients admitted at emergencydepartment with severe head trauma. J Acute Dis. 2015;4(1):68-72.

44. Gürkanlar D, Lakadamyali H, Ergun T, Yilmaz C, Yücel E, Altinörs N. Predictive value of leucocytosis in head trauma. Turk Neurosurg. 2009;19(3):211-5.

45. Fujii T, Moriel G, Kramer DR, et al. Prognostic factors of early outcome and discharge status in patients undergoing surgical intervention following traumatic intracranial hemorrhage. J Clin Neurosci. 2016;31:152-6.

46. Epstein DS, Mitra B, O'Reilly G, Rosenfeld JV, Cameron PA. Acute traumatic coagulopathy in the setting of isolated traumatic brain injury: a systematic review and meta-analysis. Injury. 2014;45:819-24. https://doi.org/10.1016/j.injur y.2014.01.011.

47. MacLeod JB, Lynn M, McKenney MG, Cohn SM, Murtha M. Early coagulopathy predicts mortality in trauma. J Trauma. 2003;55:39-44. https://doi.org/10.1097/01.TA.0000075338 .21177.EF.

48. Lustenberger T, Talving P, Kobayashi L, Inaba K, Lam L, Plurad D, Demetriades D. Time course of coagulopathy in isolated severe traumatic brain injury. Injury. 2010;41:924-8. https:// doi.org/10.1016/j.injury.2010.04.019.

49. Allard CB, Scarpelini S, Rhind SG, Baker AJ, Shek PN, Tien H, Fernando M, Tremblay L, Morrison LJ, Pinto R, Rizoli SB. Abnormal coagulation tests are associated with progression of traumatic intracranial hemorrhage. J Trauma. 2009;67:959-67. https://doi.org/10.1097/TA.0b013e3181ad5d37.

50 Talving P, Benfield R, Hadjizacharia P, Inaba K, Chan LS. Demetrios Demetriades. Coagulopathy in severe traumatic brain injury: a prospective study. J Trauma. 2009;66:55-61.

51. Bernier R, Hillary F. Trends in alcohol use during moderate and severe traumatic brain injury: 18 years of neurotrauma in Pennsylvania. Brain Inj. 2016;30(4):414-21.

52. Pandit V, Patel N, Rhee P, Kulvatunyou N, Aziz H, Green DJ, O'Keeffe T, Zangbar B, Tang A, Gries L, Friese RS, Joseph B. Effect of alcohol in traumatic brain injury: is it really protective? J Surg Res. 2014;190(2):634-9.

53. Plurad D, Demetriades D, Gruzinski G, Preston C, Chan L, Gaspard D, Margulies D, Cryer G. Motor vehicle crashes: the association of alcohol consumption with the type and severity of injuries and outcomes. J Emerg Med. 2010;38:12-7.

54. Raj R, Skrifvars MB, Kivisaari R, Hernesniemi J, Lappalainen $\mathrm{J}$, Siironen J. Acute alcohol intoxication and long-term outcome in patients with traumatic brain injury. J Neurotrauma. 2015;32:95-100.

55. Alexander S, Kerr ME, Yonas H, Marion DW. The effects of admission alcohol level on cerebral blood flow and outcomes after severe traumatic brain injury. J Neurotrauma. 2004;21:575-83.

56. Maas AI, Steyerberg EW, Butcher I, Dammers R, Lu J, Marmarou A, Mushkudiani NA, McHugh GS, Murray GD. Prognostic value of computerized tomography scan characteristics in traumatic brain injury: results from the IMPACT study. J Neurotrauma. 2007;24(2):303-14.

57. Hiler M, Czosnyka M, Hutchinson P, Balestreri M, Smielewski P, Matta B, Pickard JD. Predictive value of initial computerized 
tomography scan, intracranial pressure, and state of autoregulation in patients with traumatic brain injury. J Neurosurg. 2006;104(5):731-7.

58. Bhaskar Naidu P, Truman Srinivas M, Selvakumar K. Computed tomography predictors for in-hospital mortality in severe and moderate head injury patients. Inter Sur J. 2016;3(3):1306-9.

59. Nelson DW, Nystrom H, MacCallum RM, Thornquist B, Lilja A, Bellander BM, Rudehill A, Wanecek M, Weitzberg E. Extended analysis of early computed tomography scans of traumatic brain injured patients and relations to outcome. J Neurotrauma. 2010;27:51-64.

60. Fabbri A, Servadei F, Marchesini G, Stein SC, Vandelli A. Early predictors of unfavourable outcome in subjects with moderate head injury in the emergency department. J Neurol Neurosurg Psychiatry. 2008;79:567-73.

61. Grigorakos L, Alexopoulou A, Tzortzopoulou K, Stratouli S, Chroni D, Papadaki E, Alamanos I, Sakellaridis N. Predictors of outcome in patients with severe traumatic brain injury. J Neurosci Clin Res. 2016;1:1-4.

62. Toutant SM, Klauber MR, Marshall LF, et al. Absent or compressed basal cisterns on first CT scan: ominous predictors of outcome in severe head injury. J Neurosurg. 1984;61:691-4.

63 Wood RL, Eames R. Application of behaviour modifi cation in the rehabilitation of traumatically brain-injured patients. In: Davey G, editor. Applications of conditioning theory. New York: Methuen; 1981.p. 81-101.

64. Munoz-Sánchez MA, Murillo-Cabezas F, Cayuela-Domínguez A, Rincón-Ferrari MD, Amaya-Villar R, León-Carrión J. Skull fracture, with or without clinical signs, in mTBI is an independent risk marker for neurosurgically relevant intracranial lesion: a cohort study. Brain Inj. 2009;23:39-44.
65. Park JH, Park JE, Kim SH, Lim YC, You NK, Ahn YH, Choi H, Cho J. Outcomes of ultra-early decompressive craniectomy after severe traumatic brain injury-treatment outcomes after severe TBI. Korean J Neurotrauma. 2014;10:112-8.

66. Haselsberger K, Pucher R, Auer LM. Prognosis after acute subdural or epidural haemorrhage. Acta Neurochir (Wien). 1988;90:111-6.

67. Wilberger JE, Harris M, Diamond DL. Acute subdural hematoma: morbidity, mortality, and operative timing. J Neurosurg. 1991;74:212-8.

68. Sakas DE, Bullock MR, Teasdale GM. One-year outcome following craniotomy for traumatic hematoma in patients with fixed dilated pupils. J Neurosurg. 1995;82:961-5.

69. Zafrullah Arifin M, Gunawan W. Analysis of presurgery time as a prognostic factor in traumatic acute subdural hematoma. J Neurosurg Sci. 2013;57:277-80.

70. Matsushima K, Inaba K, Siboni S, Skiada D, Strumwasser AM, Magee GA, Sung GY, Benjaminm ER, Lam L, Demetriades D. Emergent operation for isolated severe traumatic brain injury: Does time matter? J Trauma Acute Care Surg. 2015;79:838-42.

71. Seelig JM, Becker DP, Miller JD, Greenberg RP, Ward JD, Choi SC. Traumatic acute subdural hematoma: major mortality reduction in comatose patients treated within four hours. N Engl J Med. 1981;304:1511-8.

72. Sergides IG, Whiting G, Howarth S, Hutchinson PJ. Is the recommended target of 4 hours from head injury to emergency craniotomy achievable? Br J Neurosurg. 2006;20:301-5.

73. Kotwica Z, Brzezinski J. Acute subdural hematoma in adults: an analysis of outcome in comatose patients. Acta Neurochir. 1993;121:95-9. 